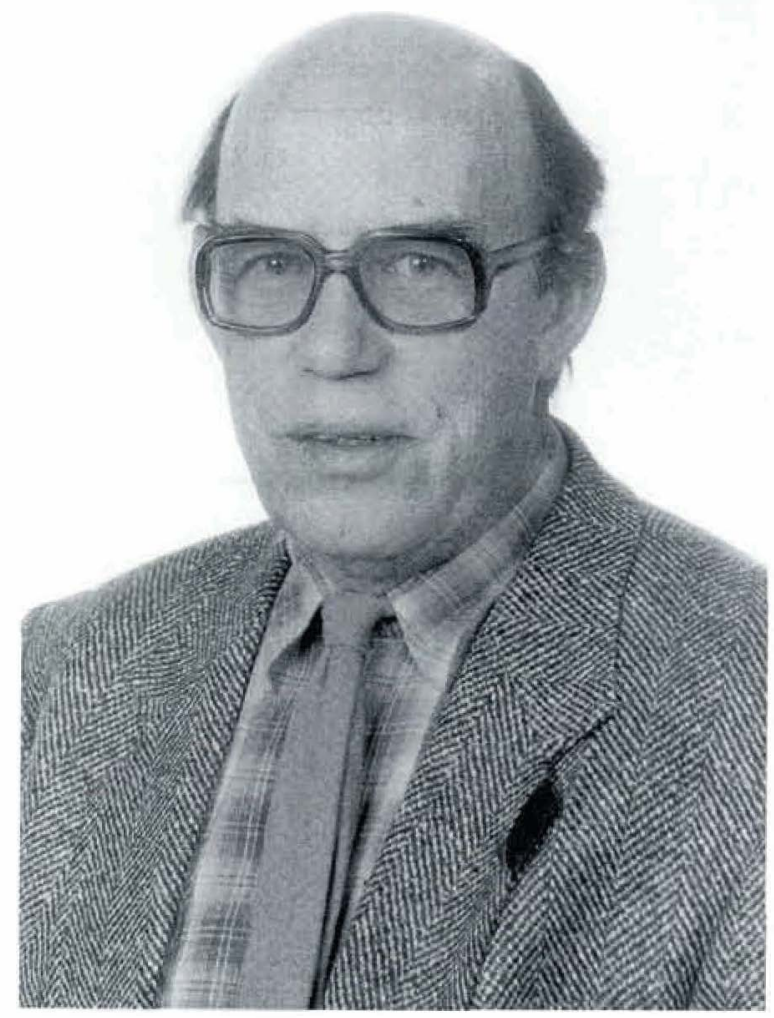

\title{
Gunnar Larsen
}

\author{
Professor of Geology \\ Geologisk Institut, Aarhus Universitet
}

On the occasion of Gunnar Larsen's retirement from the chair of sedimentary geology at Geologisk Institut. Aarhus Universitet a one day symposium was organized in September 1995 by members of staff at the department. A number of Gunnar Larsen's former students and co-workerswer einvited to give talks at the symposium and the programme was selected in order t oreflect the wide range of activitie sGunnar Lar sen has been involved in during his long and continuing career as a geologist.

The condensed version of Gunnar Larsen's curriculum virae is very short: After he graduated from Copenhagen University in 1956, he was employed as a geologist at the Geological Survey of Denmark unti] 1967, when he became professor of geology at Aarhus University.

However, this condensed CV conceals an extraordinary variety of activities. A few highlights: While at the Geological Survey he collaborated with Statens Byggeforskningsinstitut, mainly doing research on concrete stability. He has served as editor of the Bulletin of the Geological Society of Denmark (1962-69), co-editor of Sedimentary Geology (1967-84), and co-editor of Engineering Geology (1965-83). For twelve years (196981 ) he was a member of the Nature Conservancy Council (Naturlredning saidet) and 1984-92 he was a member of the Danish Natural Science Research Council. His research activities has been mainly within sedimentology, Quaternary geology and engineering geology.

All these activities were reflected in the talks at the symposium. The symposium was very well attended. More than 100 had registered for the event and dozens more showed up during the various talks. All talks were given in Danish and on the following pages some of the talks are presented in their English version.

John A. Korstgård, Geologisk Institut, Aarhus Universitet, DK-8000 Århus C. 